\title{
Avaliação do reuso de água de limpeza em uma indústria de sabão em pó sintético
}

\section{EVALUATION OF WATER REUSE OF CLEANING IN AN INDUSTRY OF SYNTHETIC SOAP POWDER}

\author{
Laurivê Antônio dos Santos Júnior ${ }^{1}$, Monike Fabiane Alves Ribeiro Lacerda ${ }^{2}$, Paulo de Tarso Ferreira \\ Sales $^{3}$, Fernando Schimidt ${ }^{4}$, Mariângela Fontes Santiago ${ }^{5}$
}

Recebido em 09 de outubro de 2012; recebido para revisão em 15 de outubro de 2012; aceito em 18 de outubro de 2012; disponivel on-line em 05 de novembro de 2012.

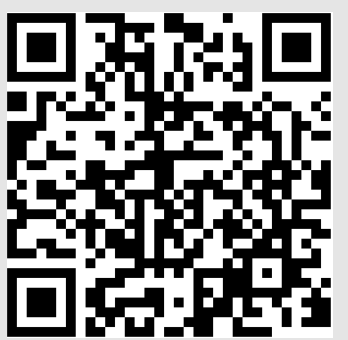

PALAVRAS CHAVES:

Reuso de água;

Indústria de sabão em pó;

Matéria ativa aniônica.

\section{KEYWORDS:}

Water reuse;

Soap powder industry;

Anionic active matter.

\begin{abstract}
RESUMO: O presente projeto teve como objetivo estudar e avaliar a reutilização de água de limpeza no processo de fabricação de detergente em pó, garantindo a qualidade ao produto, bem como diminuindo o impacto ambiental pela não geração de efluente industrial; observando-se a relação com os seguintes parâmetros: cor, turbidez, pH, alcalinidade, DQO, fósforo total e matéria ativa aniônica (\% p/p). Foram coletadas 10 amostras do efluente no reservatório de água de lavagem dos tanques de produção de detergente em pó, como também foram realizadas 10 coletas do pó base produzido com a água de lavagem dos tanques de produção, com intuito de comparar a quantidade de tenso ativo aniônico presente em ambas as amostras. Os resultados mostraram que houve um aumento cerca de $1 \%$ na quantidade de matéria ativa aniônica no pó base produzido, evidenciando uma melhoria na qualidade do produto, sem aumento do custo com matéria-prima. A reutilização da água de lavagem dos tanques de produção permitiu a produção de um produto de melhor qualidade, economia de matéria-prima; tornando possível a não geração de resíduo industrial, diminuindo assim o impacto ambiental desse tipo efluente.

ABSTRACT: The present project aimed to study and evaluate the reuse of water in the cleaning process of making detergent powder, ensuring the product quality as well as reducing the environmental impact by not generating industrial effluent; observing the relationship with following parameters: color, turbidity, $\mathrm{pH}$, alkalinity, $\mathrm{COD}$, total phosphorus and anionic active matter (\% w / w). 10 samples were collected in the effluent water reservoir tank washing production of detergent powder, as well as collections were performed 10 base powder produced with the washing water tanks production, aiming to compare the amount of active tense anion present in both samples. The results showed that there was an approximately $1 \%$ increase in the amount of anionic active matter in the base powder produced, showing an improvement in product quality without increasing the cost of raw materials. The reuse of washing water tanks production has enabled the production of a product of better quality, economy of raw material, making possible the generation of non-industrial waste, thereby reducing the environmental impact of such effluent.
\end{abstract}

\footnotetext{
* Contato com os autores:

${ }^{1}$ e-mail : laurivejunior@hotmail.com (L. A. dos Santos Júnior)

Tecnólogo em Química Industrial - Instituto Federal de Goiás - IFG

22e-mail : monikefabiane@gmail.com (M. F. A. R. Lacerda)

Tecnóloga em Saneamento Ambiental - Instituto Federal de Goiás - IFG

33e-mail : paulo@tecpam.com.br (P.T. F. Sales) da Escola de Engenharia Civil da Universidade Federal de Goiás - UFG.

${ }^{4}$ e-mail : mariangelafs@gmail.com (F. Schimidt)

Professor do Instituto Federal de Goiás - IFG.

${ }^{5}$ e-mail : mariangelafs@gmail.com (M. F. Santiago)

Professora da Faculdade de Farmácia da Universidade Federal de Goiás - UFG.
}

Tecnólogo em Química Industrial, Mestre em Engenharia de Meio Ambiente - PPGEMA - Programa de Pós Graduação em Engenharia de Meio Ambiente 


\section{INTRODUÇÃO}

A partir de 1971, já havia referências que o reuso de água industrial poderia ser uma maneira de diminuir a poluição ambiental (Rey et al., 1971). Embora exista a preocupação universal em se evitar episódios de contaminação ambiental, estes eventos prejudiciais continuam acontecendo, principalmente porque, em função dos fatores acima comentados, grande parte dos processos produtivos são intrinsecamente poluentes. Ao longo das décadas, a atividade industrial tem produzido rejeitos gasosos, líquidos e sólidos nocivos ao meio ambiente (Freire et al., 2000). Os processos industriais que utilizam grandes volumes de água contribuem significativamente para a contaminação dos corpos d'água, principalmente pela ausência de tratamento para os grandes volumes de efluentes líquidos produzidos. Dentro deste contexto, uma importante parcela do processo de contaminação no Estado de Goiás, pode ser atribuída às atividades das diversas indústrias farmacêuticas e de domisanitários principalmente a partir do final da década de 90.

Os detergentes modernos foram desenvolvidos para substituir o sabão (Atkins; Jones, 1997) e essas formulações comerciais modernass são misturas, sendo que o seu componente mais importante é o surfactante ou agente tensoativo. O tensoativo sintético de maior produção mundial é o alquilbenzeno linear sulfonado (LAS), dado o seu emprego na produção de uma elevada percentagem de detergentes, vindo em substituição do alquilbenzeno sulfonado não linear (ABS), composto de baixa biodegradabilidade (Cunha et al., 2001). Os tensoativos quando em solução, devido à presença do grupo lipofílico, ocupam preferencialmente a superfície do líquido, diminuindo a força de coesão entre as moléculas do solvente e, consequentemente, diminuindo a tensão superficial (Behring et al., 2004). Segundo Shreve e Brink Jr (1997), os surfactantes dos detergentes efetuam na lavagem a ação de limpeza primária e de espumejamento mediante o mecanismo de redução da tensão superficial. De acordo com Layman (1984) citado por Osorio e Oliveira (2001), o teor de tensoativos numa caixa de detergente em pó para lavanderia é da ordem de 17 a 32\%, em massa, em países da América do Sul.

Bigardi e colaboradores (2003) relataram as condições exigidas para a biodegradação de tensoativos em que a degradação do mesmo pode não ser completa, indicando que os resultados dos ensaios realizados em bancada são diferentes dos ensaios realizados em uma Estação de Tratamento de Esgoto. A legislação atual a respeito da biodegradação dos detergentes está na Portaria no 874, de 5/11/98, da Vigilância Sanitária do Ministério da Saúde que fixa como padrão de referência de biodegradabilidade o n-dodecilbenzeno sulfonato de sódio e considera biodegradáveis substâncias tensoativas aniônicas com grau de biodegradabilidade superior a $90 \%$ em relação ao padrão, em um período máximo de 14 dias, dentro de um tempo total de 19 dias e sob condições padrão de ensaio.

O processo de fabricação do detergente em pó está apresentado na Figura 1 e tem três passos principais: preparação do slurry, secagem em torre de atomização e tratamento dos grãos. As matérias-primas são, geralmente, líquidas ou produtos em pó solúveis em água. O processo se inicia com a adição de água de reuso ao crutcher (tanque de preparação) e logo após, solução de hidróxido de sódio é introduzida no tanque. O agitador é ligado e então o ácido sulfônico é então adicionado.

A reação de neutralização do ácido sulfônico pela soda cáustica é exotérmica e isso permite que a temperatura no interior do tanque aumente (até aproximadamente 50으. ).

As matérias-primas líquidas foram misturadas às matérias-primas sólidas a quente (cerca de $80^{\circ} \mathrm{C}$ ) e, portanto, a temperatura foi controlada. Uma serpentina instalada dentro do tanque por onde circula vapor de água fornecido por caldeira permite que o controle de temperatura seja feito abrindo ou fechando uma válvula.

É feita uma pré-mistura do corante e branqueador os quais são dissolvidos em água antes de serem adicionados ao crutcher. A mistura é então adicionada. A agitação é aumentada no painel de controle e o silicato de sódio é introduzido no tanque. Tripolifosfato de sódio é adicionado logo a seguir. A agitação é novamente aumentada e o sulfato de sódio é introduzido no tanque, por meio de transportador mecânico tipo rosca-sem-fim.

O efluente gerado é relativo ao processo de limpeza dos maquinários envolvidos no processo de fabricação, são lançados em um reservatório metálico de 1000 L. Antes da implantação do processo de reuso de água de limpeza, o efluente era tratado com neutralização (utilizando-se $\mathrm{H}_{2} \mathrm{SO}_{4}$ ), seguido de decantação e a água residuária então era lançada ao sistema público de coleta de esgoto.

Em geral, a quantidade de água usada na limpeza é totalmente usada na produção de sabão em pó sintético, não sendo necessária a adição de água no processo, portanto, somente é adicionado água no processo de limpeza dos equipamentos.

A Resolução CONAMA (Conselho Nacional de Meio Ambiente) no 359, de 29 de abril de 2005, dispõe sobre a regulamentação do teor de fósforo em detergentes em pó, estabelecendo critérios para a utilização de fósforo na formulação de detergentes em 
pó para o uso no mercado nacional, visando à redução e eventual eliminação do aporte de fósforo dessa fonte nos corpos de água. No artigo 3o da mesma resolução regulamenta que o aporte de fósforo oriundo de detergentes em pó será controlado por meio do estabelecimento de limites da concentração máxima de fósforo por produto e da média ponderada de fósforo por grupo fabricante/importador.

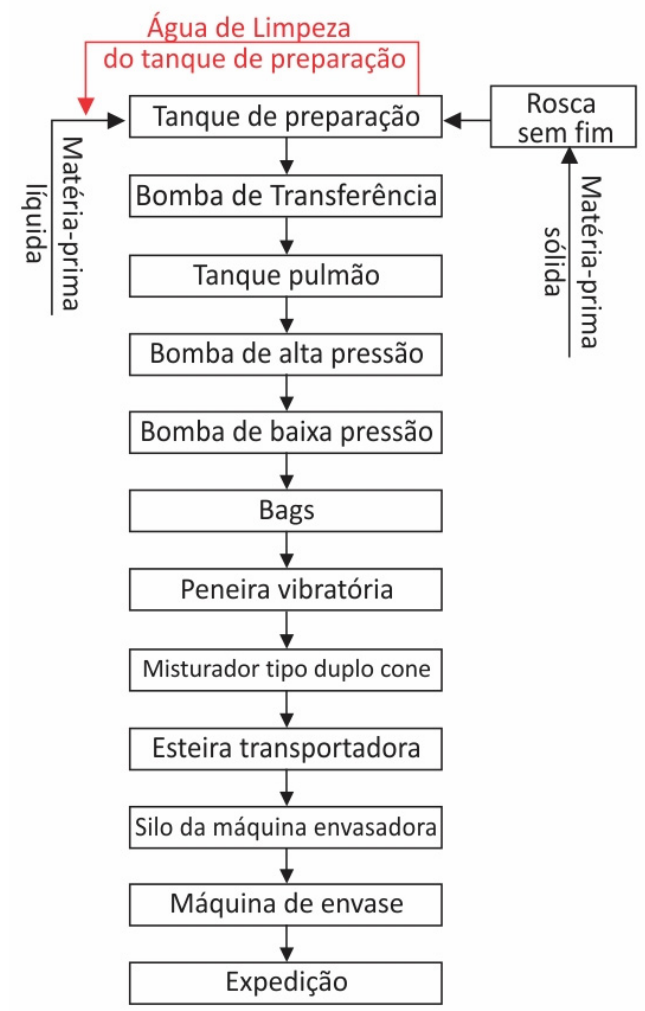

Figura 1: Fluxograma do processo de produção de detergente em pó sintético.

A eutrofização de lagos e represas é um processo de degradação que tem início com a entrada de nutrientes, especialmente nitrogênio e fósforo, trazidos pela drenagem superficial de áreas agrícolas e por descargas industriais e urbanas não tratadas. Dos nutrientes carreados ou despejados nos corpos $d$ água, o fósforo é considerado como o mais limitante (Souza et al., 2007). O transporte de fósforo de solos para ambientes aquáticos, via escoamento superficial e subsuperficial, pode criar condições nutricionais favoráveis ao crescimento acima do normal de fito e zooplâncton, além de plantas aquáticas superiores. Este crescimento exagerado de biomassa causa aumento na demanda biológica de oxigênio, alteração de $\mathrm{pH}$, turbidez da água, liberação de toxinas, que podem causar morte de peixes, de animais etc. (Loures et al., 2006). A superfície da água fica recoberta por uma camada tão espessa desses organismos, que a luz solar não consegue mais atravessá-la. As algas da parte inferior morrem e passam a sofrer degradação por bactérias aeróbicas (Botkin; Keller, 2000).

Embora a água seja um recurso natural renovável, a consciência de sua escassez como fonte de manutenção da vida, seja nas atividades produtivas, agropastoris e até mesmo para o abastecimento público das populações, tem levado os países a tratarem seus recursos hídricos como se não fossem renováveis, institucionalizando e sistematizando políticas para sua utilização e descarte (Fink; Santos, 2003). O reuso de água não potável para fins industriais consiste na reutilização industrial desse efluente, em vez de sua disposição no meio ambiente. Evidentemente, o uso que será feito desse esgoto tratado definirá os processos e as operações unitárias adicionais para o acondicionamento desse esgoto. Uma particularidade, incluída nessa classificação (reuso não potável para fins industriais), é a da reciclagem. Aqui podem ser enquadrados os casos de reuso interno às instalações industriais, com o objetivo de atender as demandas da própria indústria ou controlar a poluição (Braga Filho; Mancuso, 2003).

O objetivo desse trabalho foi avaliar o reuso de água de limpeza dos maquinários envolvidos no processo de fabricação de sabão em pó sintético, tendo como comparação a quantidade de matéria ativa aniônica encontrada no pó base para fabricação do produto final.

\section{METODOLOGIA}

\subsection{COLETA DAS AMOSTRAS}

Este trabalho foi realizado com a coleta de amostras do efluente de uma indústria de detergente em pó, situada no município de Aparecida de Goiânia. Para realização dos experimentos, foram coletadas 10 amostras de 2,0 L cada, periodicamente de 3 em 3 dias no reservatório de água de lavagem dos tanques de produção de detergente em pó sintético, num processo de amostragem simples, em que foram amostrados volumes iguais de efluente a cada processo de batelada realizado na indústria. $O$ efluente coletado foi acondicionado em frascos de polietileno e mantido sob refrigeração a 4ㅇ C (Santiago, 1999).

Foram realizadas coletas de pó base confeccionados com a água de reuso, retirados da boca da torre de sopragem de detergente em pó e procedidas análises em laboratório com o intuito de verificar o teor de matéria ativa aniônica presente. 


\subsection{MÉTODOS ANALÍTICOS DE CARACTERIZAÇÃO DAS AMOSTRAS}

Os equipamentos utilizados foram Turbidímetro marca Marconi modelo MA TB 1000, Condutivímetro marca Digimed modelo CD-20, Espectrofotômetro marca Fentom modelo 700 Plus, Potenciômetro marca Tecnal modelo TEC-2 (com eletrodo de $\mathrm{Ag} / \mathrm{AgCl}$ ) e Colorímetro marca $\mathrm{HACH}$ modelo DR/890. O Quadro 1 relaciona os tipos de análises efetuadas na caracterização do efluente in natura.

\subsection{PREPARO DAS AMOSTRAS}

Antes da realização dos procedimentos analíticos, as amostras foram retiradas da refrigeração e deixadas em ambiente até à equalização da temperatura com a temperatura ambiente. Todas as análises foram feitas em temperatura ambiente, exceto a análise de $\mathrm{pH}$, que teve o resultado corrigido para 20 $\mathrm{C}$, sendo medido in loco.

Para a análise de fósforo total, toda a vidraria foi lavada com ácido clorídrico e posteriormente foram lavados com água destilada. Cabe salientar que as vidrarias para realização dessa análise foram separadas, para evitar contaminação cruzada.

\begin{tabular}{|c|c|c|}
\hline Característica & Tipo Análise & Referência \\
\hline Turbidez & Análise em turbidímetro & 2130 B (APHA, 1995) \\
\hline Condutividade & Análise em condutivímetro & 2510 B (APHA, 1995) \\
\hline $\mathrm{pH}$ & $\begin{array}{l}\text { Análise potenciométrica direta } \\
\text { (eletrodo de } \mathrm{Ag} / \mathrm{AgCl} \text { ) }\end{array}$ & $4500-H^{+}$(APHA, 1995) \\
\hline Cor & Análise em colorímetro & 2120 C (APHA, 1995) \\
\hline Acidez & Análise titrimétrica (indicador de fenolftaleína) & 2310 B (APHA, 1995) \\
\hline Alcalinidade & $\begin{array}{l}\text { Análise titrimétrica (indicador de fenolftaleína para } \\
\text { carbonatos e alaranjado de metila para carbonatos } \\
\text { totais). }\end{array}$ & 2320 B (APHA, 1995) \\
\hline $\begin{array}{c}\text { DQO (Demanda } \\
\text { Química de Oxigênio) }\end{array}$ & Análise colorimétrica (método do dicromato) & 5220 D (APHA, 1995) \\
\hline Fósforo Total & Análise colorimétrica (método do ácido ascórbico) & 4500 B (APHA, 1995) \\
\hline Matéria Ativa Aniônica & Análise titrimétrica (método do indicador misto) & $\begin{array}{c}\text { Portaria no } 393 \text { da ANVISA } \\
\text { Anexo A. }\end{array}$ \\
\hline
\end{tabular}

\section{RESULTADOS E DISCUSSÃO}

Todas as amostras apresentaram pH acima de 10,5; evidenciando condições consideravelmente alcalinas da amostra. Isso é justificado pelos valores altos de alcalinidade encontrados. Segundo Von Sperling (2005), valores de pH elevado possibilitam incrustações nas tubulações e peças da rede de água e possibilitam a precipitação de metais e valores de $\mathrm{pH}$ maiores que 9,4 estão relacionados à presença de íons carbonatos $\mathrm{e}$ hidróxidos. Valores de $\mathrm{pH}$ afastados da neutralidade podem afetar a vida aquática (exemplo peixes) e os microrganismos responsáveis pelo tratamento dos esgotos. Os elevados valores de $\mathrm{pH}$ e alcalinidade encontrados são devidos à presença na formulação do slurry de silicato de sódio alcalino, tripolifosfato de sódio (sal alcalino) e um excesso de hidróxido de sódio necessário para garantir a total neutralização do ácido linear alquilbenzeno sulfônico. Assim, o pH elevado é devido à presença de íons hidroxila e carbonato além da alcalinidade devida ao silicato de sódio alcalino e ao tripolifosfato de sódio.O tripolifosfato de sódio apresenta $\mathrm{pH}$ 9,5-10,2 (solução aquosa 1\%) enquanto o silicato de sódio alcalino apresenta alcalinidade total como $\mathrm{Na}_{2} \mathrm{O} 12,00$ a $12,80 \%$ conforme laudos do fornecedor. A Figura 2 relaciona os valores de $\mathrm{pH}$ e de alcalinidade das amostras. Os valores de $\mathrm{pH}$ estão acima dos parâmetros de lançamento de efluente, de acordo com a resolução no 357 do CONAMA. 


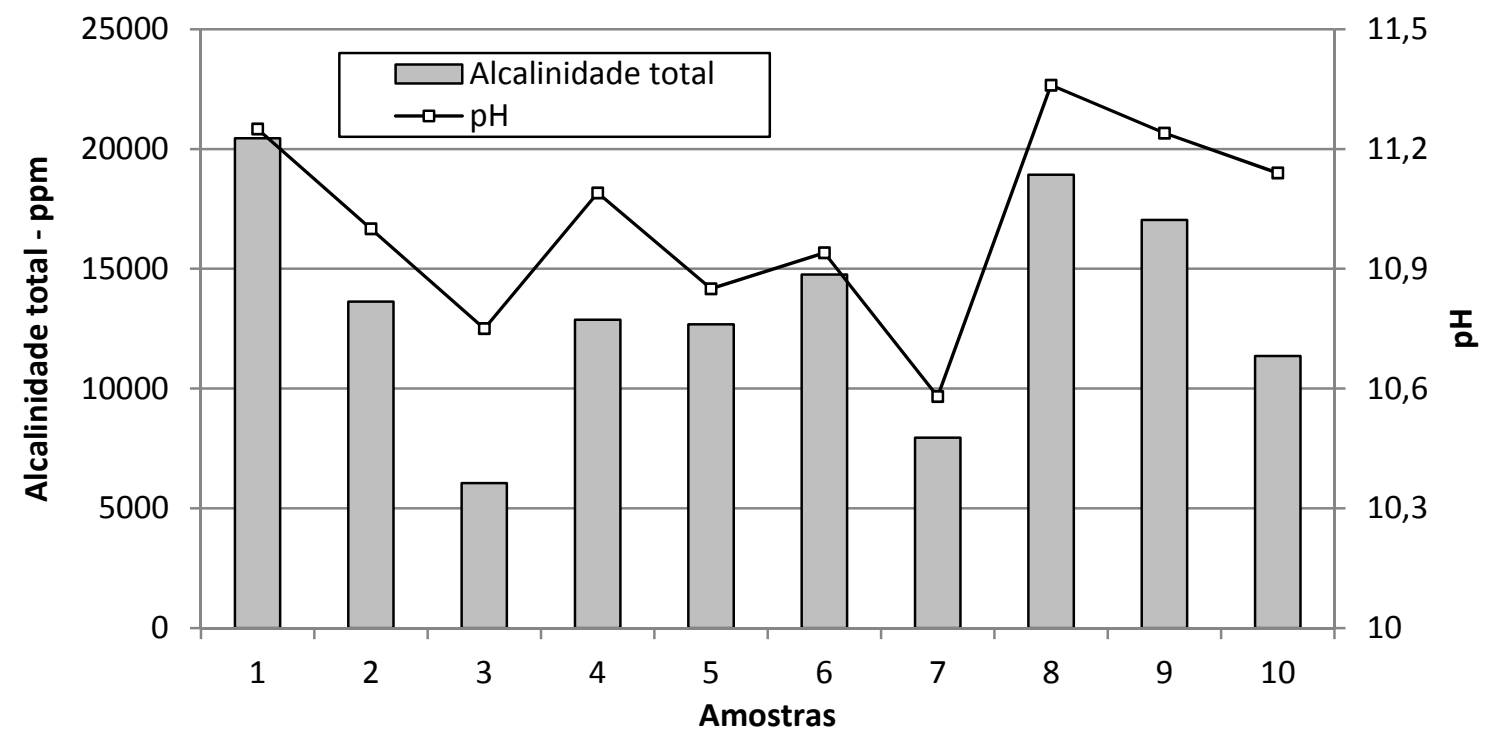

Figura 2: Valores de $\mathrm{pH}$ e de alcalinidade para das amostras.

Todas as amostras apresentaram turbidez elevada (Figura 3). Conforme Von Sperling (2005) em corpos d' água, a turbidez pode reduzir a penetração da luz, prejudicando a fotossíntese. Com exceção das amostras 2 e 8, as amostras apresentaram turbidez com valores consideravelmente próximos . Quanto às amostras 2 e 8, esta variação é devida à variação da quantidade de água utilizada para lavar os tanques de produção de detergente em pó, isto é, utilizou-se menos água resultando em um efluente mais concentrado e, consequentemente, com maior turbidez. Grande quantidade de material suspenso presente nas amostras é devida ao carbonato de cálcio usado na formulação, o que é acentuado pelo $\mathrm{pH}$ alto de todas as amostras.
A cor nas amostras de efluente é devido ao emprego de corantes na formulação do detergente em pó. Também é devido ao componente turbidez presente nos resultados de cor aparente (Figura 3). A variação encontrada nos valores de cor verdadeira é relativa à variação da quantidade de água utilizada para a lavagem dos tanques de produção de detergente em pó (ao se utilizar mais água para se lavar os tanques obtém-se um efluente com menos corante, etc.) e da quantidade de água de lavagem reutilizada do reservatório na produção do slurry. De acordo com Braile e Cavalcanti (1979), a cor em águas residuárias é provocada por corantes orgânicos e inorgânicos.

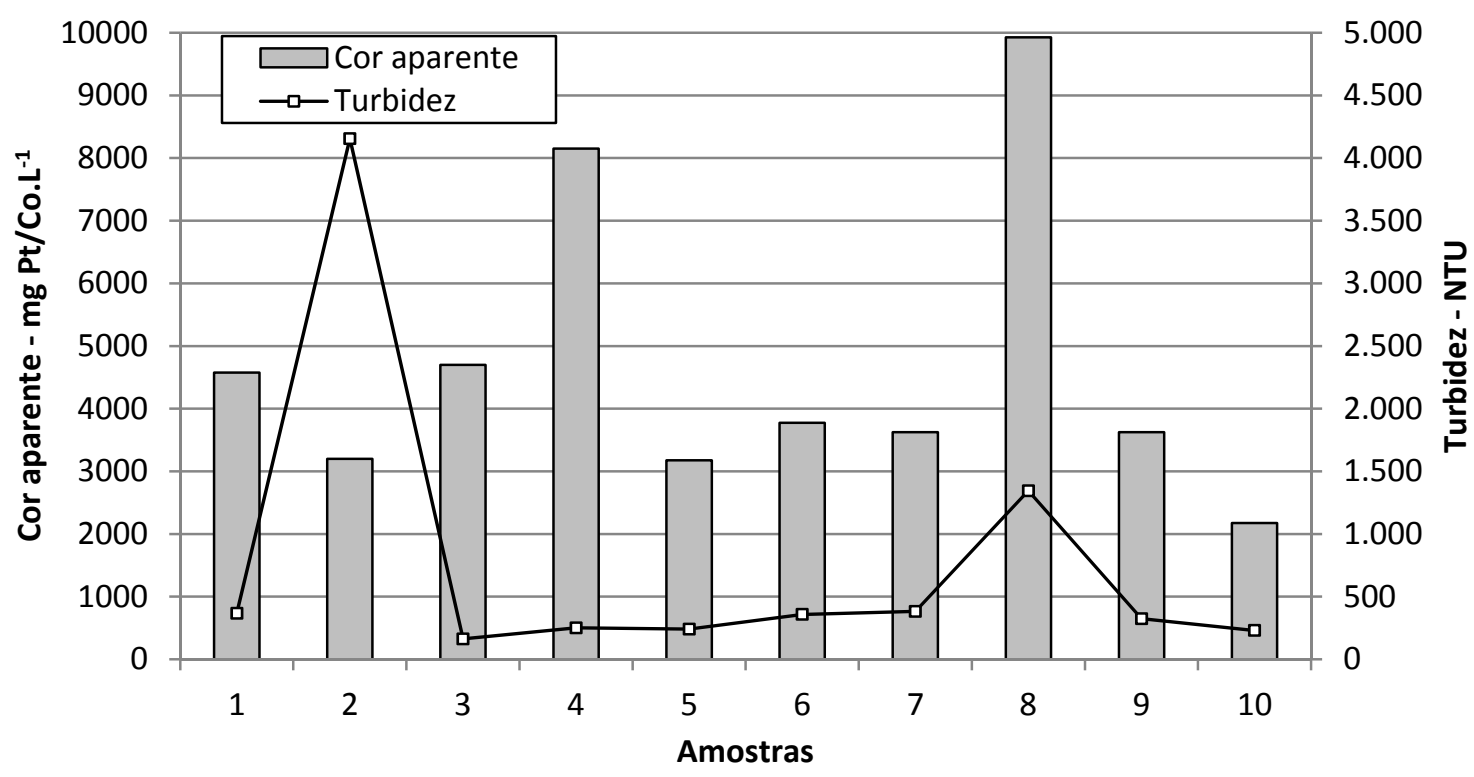

Figura 3: Resultados de Cor Verdadeira e Turbidez das amostras. 
Os valores de condutividade encontrados

(Figura 4) são consequências da presença de sais inorgânicos no efluente como o sulfato de sódio, que é um eletrólito forte. Com exceção das amostras 2, 3 e 7, as outras amostras apresentaram valores de condutividade muito próximos. Quanto às amostras 2, 3 e 7 , há uma quantidade menor de eletrólitos na solução (utilizou-se menos sulfato de sódio nessas formulações), evidenciando menores valores de condutividade. Vogel (1981) comenta que quando uma solução de um eletrólito é diluída, a condutividade decresce porque menos íons estão presentes por $\mathrm{cm}^{3}$ da solução que carrega a corrente.

A oxidação dos materiais de origem orgânica nas amostras resultou em altos valores de DQO (Figura 4) devido à quantidade empregada desses componentes na formulação. As substâncias orgânicas presentes nas amostras são os corantes, o branqueador óptico e a matéria ativa aniônica (linear alquil benzeno sulfonato de sódio). Todas as amostras (Figura 3) apresentaram valores altos de DQO (acima de 11000,00 mg de $\mathrm{O}_{2} \cdot \mathrm{L}^{-1}$ ). As amostras 4, 6 e 7 apresentaram valores menores de DQO, quando comparadas às outras amostras, devido ao emprego de água limpa para a lavagem dos tanques, o que influenciou na quantidade de matéria orgânica nas amostras.

De acordo com Metcalf e Eddy (1985), outro nome pelo qual se conhecem os agentes tensoativos é: Substâncias ativas ao azul metileno (SAAM). O teor de tensoativos aniônicos das amostras pó base mostrou-se relativamente alto (Figura 5), acima da média de $8 \%$. Entretanto, não foi possível estabelecer uma relação entre os teores de matéria ativa aniônica presente no efluente e no pó base.

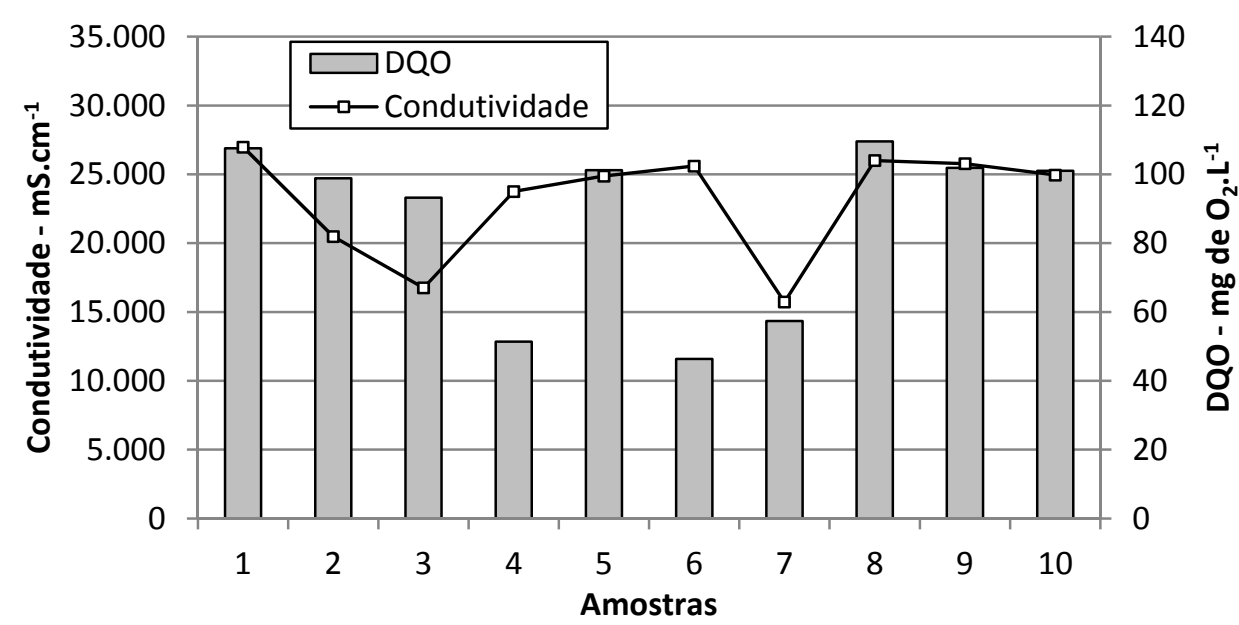

Figura 4: Resultados de condutividade elétrica e DQO para as amostras.

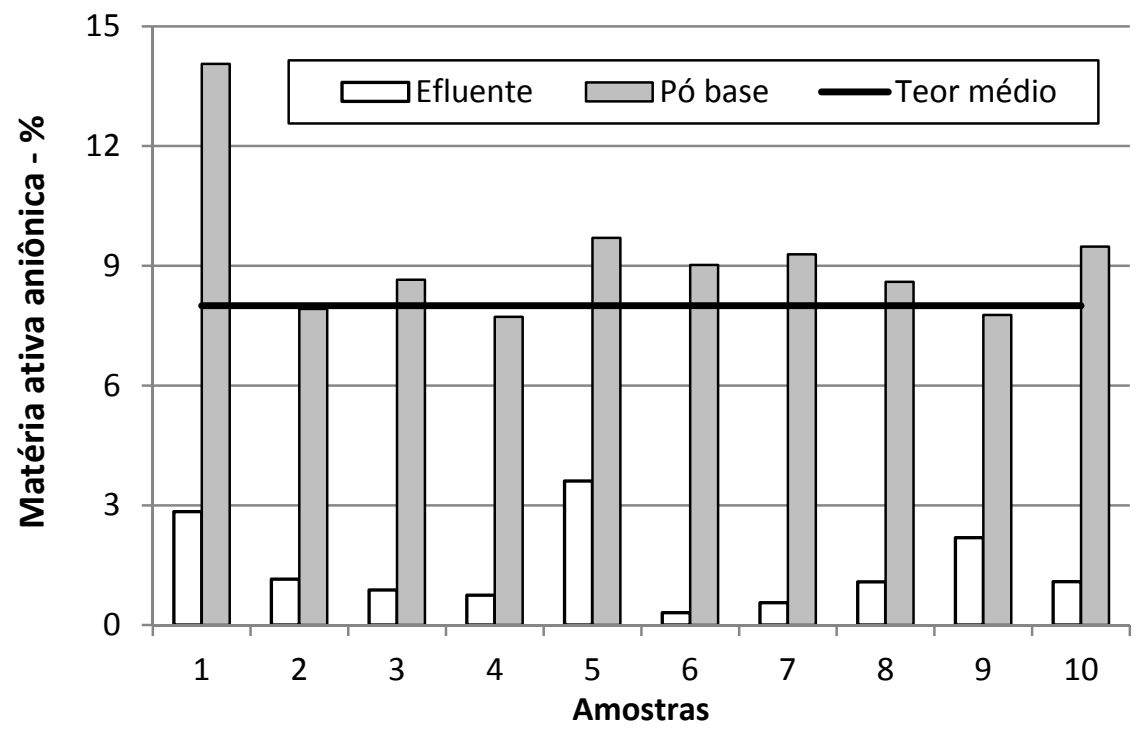

Figura 5: Resultados de matéria ativa aniônica no efluente e no pó base. 


\section{CONCLUSÕES}

As amostras de efluente da indústria de detergente em pó apresentaram características físicoquímicas que tornariam o seu tratamento Bastante complexo e oneroso. Assim, a recirculação deste efluente no processo de produção de detergente em pó sintético em um menor volume a ser disposto no meio ambiente. Os resultados deste trabalho mostraram que no processo de fabricação de detergente em pó é possível reutilizar o efluente resultante da lavagem dos tanques, pois a alcalinidade, o $\mathrm{pH}$ alcalino, o teor de matéria ativa aniônica, o teor de fósforo total apresentados nas amostras de efluente são vantajosos para o processo de fabricação. Além de que a cor, turbidez e DQO apresentados pelo efluente são característicos e não constituem barreira à reutilização no processo. A reutilização da água de lavagem dos tanques de produção permite a economia de tensoativo porque se pode utilizar menor quantidade de ácido sulfônico, obtendo o mesmo teor de matéria ativa aniônica.

Uma observação importante é que o reuso de água de processo permite a economia de água e a não geração de resíduo industrial, pois o efluente produzido é utilizado em formulações posteriores dispensando qualquer tipo de tratamento físico-químico ou biológico. A reutilização da água de lavagem dos tanques de produção permite produzir um detergente em pó com a mesma qualidade, do que quando se utilizou água limpa, além de que o pó produzido com água de processo apresenta um teor maior de tensoativo aniônico, justificando uma melhor qualidade do produto final. 0 processo produtivo de detergente não necessita de água com características daquelas exigidas por outros processos industriais e o efluente adequou-se perfeitamente e com sucesso às necessidades do processo.

\section{AGRADECIMENTOS}

Edital MCT/CNPq/CT-Hidro no 14/2005, International Foundation of Science/W3433-1(IFS) e Centro Brasileiro-Europeu para Sustentabilidade BECS (Brazilian-European Center for Sustainability).

\section{REFERÊNCIAS BIBLIOGRÁFICAS}

ANVISA - Agência de Vigilância Sanitária do Ministério da Saúde. Portaria no 393 de 15 de maio de 1998: Determinação de tensoativos aniônicos em produtos comerciais e extratos. Anexo A.
Portaria no 874 , de 5 de novembro de 1998, ANVISA. Biodegradabilidade dos tensoativos aniônicos para produtos saneantes domissanitários. Disponível em < http://www.anvisa.gov.br/legis/portarias/874_98.htm>, acessado dia $16 / 10 / 2012$, às $8: 30 \mathrm{~h}$

APHA, AWWA and WPCF Standard Methods for the Examination of Water and Wastewater, Eaton, A.D; Clesceri, L. S., Greenberg, A. E. (Eds.). $19^{\text {th }}$ Edition American Public Health Association, 1995.

ATKINS, P. W.; JONES, L. L. Chemistry - Molecules, Matter and Change. $3^{\text {rd }}$ ed. New York: W. H. Freeman and Co.,1997.

BEHRING, J.L.; LUCAS, M.; MACHADO, C.; BARCELLOS, I.O. Adaptação no método do peso da gota para determinação da tensão superficial: Um método simplificado para a quantificação da CMC de surfactantes no ensino da química.Blumenau: Química Nova, vol. 27, № 3, p.492-495, 2004.

BIGARDI, T.A.R.; NUNES, A.J.T.; CARRA, L.P.; FADINI, P.S. Destino de surfactantes aniônicos em ETE do tipo lagoa aerada seguida de lagoa de decantação. Campinas: Engenharia Sanitária e Ambiental, vol.8, № 1, p. 45-48, 2003.

BOTKIN, D. B.; KELLER, E. A.Environmental Science - Earth as a Living Planet. $3^{\text {rd }}$ ed. New York: John Wiley \& Sons, p. 421, 2000.

BRAILE, P.M.; CAVALCANTI, J.E.W.A. Manual de tratamento de águas residuárias industriais. São Paulo, CETESB, p.764,1979.

BREGA FILHO, D. ; MANCUSO, P. C. S. Conceito de reuso de água. In: Reuso de água; Capítulo 2. Eds. P. C. Sanches Mancuso \& H. Felício dos Santos. Universidade de São Paulo - Faculdade de Saúde Pública, Associação Brasileira de Engenharia Sanitária e Ambiental - ABES. São Paulo, 2002.

CONAMA - Conselho Nacional do Meio Ambiente. Resolução № 359, de 29 de Abril de 2005. Dispõe sobre a regulamentação do teor de fósforo em detergentes em pó para uso em todo o território nacional e dá outras providências. Brasil, 2005.

CUNHA, C.P.; LOBATO, N.; DIAS, S. Problemática dos tensioactivos na indústria de produção de detergentes em Portugal. Lisboa: Universidade Técnica de Lisboa, 2001.

CUNHA, C.P.; LOBATO, N.; DIAS, S. Problemática dos tensioactivos na indústria de produção de detergentes em Portugal. Lisboa: Universidade Técnica de Lisboa, 2001.

FINK, D. R. ; SANTOS, H. F. A legislação de reuso da água. In: Reuso de água; Capítulo 8. Eds. P. C. Sanches Mancuso \& H. Felício dos Santos. Universidade de São Paulo - Faculdade de Saúde Pública, Associação Brasileira de Engenharia Sanitária e Ambiental - ABES. São Paulo, 2002.

FREIRE R. S. , PELEGRINI R., KUBOTA L. T. ; DURÁN, N.; PERALTA-ZAMORA ,P., N Novas tendências para o tratamento de resíduos industriais contendo espécies organocloradas, Química. Nova, 23, 4, 504-511, 2000.

LOURES, A.P.S.; SOARES, A.A.; MATOS, A.T.; CECON, P.R.; PEREIRA, O.G. Remoção de fósforo em sistema de tratamento de esgoto doméstico, por escoamento superficial.Campina Grande: Revista Brasileira de Engenharia Agrícola e Ambiental, v.10, n-3, p.706-714, 2006.

METCALF \& EDDY, Inc. Ingeniería sanitaria: Tratamiento, evacuácion y reutilización de aguas residuales. $2^{\mathrm{a}}$ ed. Revisada por TCHOBANOGLOUS, G. Barcelona: McGraw-Hill, Editorial Labor S.A., 1985. 
OSORIO, K.L.; OLIVEIRA, W. Polifosfatos em detergentes em pó comerciais. São Paulo: Química Nova, vol. 24, no 5, p.700-708, 2001.

Rey, G.; Lacy, W. J.; Cywin A. Industrial water reuse. Future pollution solution. Environmental Science \& Technology 5 (9), 760-765, 1971.

SANTIAGO, M.F. Estudo de substâncias de baixa massa molar que mimetizam as fenoloxidases com aplicações em tratamentos de efluentes industriais, Tese de doutorado, Universidade Estadual de Campinas, 1999.

SHREVE, R. N.; BRINK JR., J. A. Indústria de Processos Químicos. Tradução: MACEDO, H., 4a Ed., Rio de Janeiro: Editora Guanabara Koogan, 1997.

SOUZA, R.A.S.; ARAÚJO, S.R.; JESUS, V.A.M.; MARQUES, J.J.; CURI, N.; GUERREIRO, M.C. Frações de fosfato em reservatórios de água em Lavras - MG. Lavras: Ciências Agrotécnicas, v.31, no 2, p. 357-365, 2007.

VOGEL, A. I. Química Analítica Quantitativa. 5 ed, São Paulo, Mestre Jou, 1981.

VON SPERLING, Marcos. Introdução à qualidade das águas e ao tratamento de esgotos. 3 ed. Belo Horizonte: Departamento de Engenharia Sanitária e Ambiental; Universidade Federal de Minas Gerais; 2005. 